\title{
Correlación de carga viral con prueba RT-PCR en infección por SARS-CoV-2 y hallazgos en tomografía computarizada de tórax
}

\section{Correlation of viral load in RT-PCR test for SARS-CoV-2 infection and specific findings in chest computed tomography}

\author{
Carolina González Vergara, ${ }^{*}, \|$ Rosa Esther Arias Marin, ${ }^{\neq}$ \\ Jorge Villalón De la Rosa, ${ }^{\S}$ Mariana Delgado Nava, ${ }^{\circledR}$ Eric Misael Saucedo Moreno, \\ Catherine V Rodríguez Ortíz, " Daniel Guerrero Enciso, "Carolina Andrea Pérez Cruz," \\ Brenda A Domínguez Ruíz, " Rubén Uriostegui Flores"
}

Citar como: González VC, Arias MRE, Villalón DRJ, Delgado NM, Saucedo MEM, Rodríguez OCV et al. Correlación de carga viral con prueba RT-PCR en infección por SARS-CoV-2 y hallazgos en tomografía computarizada de tórax. Acta Med. 2020; 18 (4): 382-389. https://dx.doi.org/10.35366/97264

\section{Resumen}

El $13.8 \%$ de los pacientes afectados por el virus SARS-CoV-2 evolucionan a enfermedad grave, por lo que la detección temprana del RNA viral es necesaria para lograr contener las fuentes de infección y la progresión de la enfermedad. La replicación de la carga viral tiene relación directa con la progresión de los hallazgos tomográficos, que corresponden al daño pulmonar ocasionado por SARS-CoV-2. Objetivo: Correlacionar los hallazgos tomográficos específicos de lesión pulmonar con la estimación de la carga viral determinada por RT-PCR, cualitativa y cuantitativamente y definir si están relacionados al momento del diagnóstico. Material y métodos: Estudio descriptivo, transversal realizado en el Hospital Ángeles Mocel de la Ciudad de México, con una cohorte de 358 pacientes con una muestra total estudiada de 74. Resultados: La tomografía computada (TC) fue positiva en 93\%; edad media global 50.03; 71.6\% masculinos. Replicación viral media: 25.5 réplicas sobre 40 y cualitativa moderada en $55.4 \%$. No hubo diferencia significativa para ninguna de las variables estudiadas entre cada uno de los hallazgos tomográficos y la carga viral. Conclusión: A pesar de la alta sensibilidad probada de TC, no está indicada aún como estudio de detección y se requiere de mayor número de estudios para establecerla como factor pronóstico.

Palabras clave: SARS, SARS-CoV-2, COVID, RT-PCR, PCR, TC COVID.

\section{Abstract}

Of all patients infected with the SARS-CoV-2 virus, $13.8 \%$ evolve to a critical illness; for this reason, an early detection of the viral RNA is needed to contain the sources of infection and progression of the disease. The viral load replication has a direct relationship to the progress of tomographic manifestations corresponding to pulmonary damage produced by SARS-CoV-2 infection. Objective: To correlate specific tomographic findings of pulmonary damage to the viral load estimation determined by quantitative and qualitative RTPCR test and to define if there is a relationship at the time of diagnosis of COVID-19 disease. Material and methods: Cross-sectional descriptive study at Hospital Ángeles Mocel in Mexico City with an original cohort of 358 patients with a total sample of 74 . Results: CT was positive in $93 \%$; global average age $50.03,71.6 \%$ male. Mean viral replication 25.5 copies over 40 and moderate qualitative at $55.4 \%$. There is no significant difference for any of the studied variables between each of the tomographic findings and viral load. Conclusion: Despite high sensibility proved by CT, it is not yet indicated as a screening tool, and a higher amount of studies are required to establish it as a prognostic factor.

Keywords: SARS, SARS-CoV-2, COVID, RT-PCR, PCR, CT COVID.

\footnotetext{
* Profesor de Radiología, Jefe de Educación Médica.

₹ Patóloga Clínica, Jefe de Laboratorio.

$\S$ Departamento de Medicina Interna.

" Cirujano General.

॥ Departamento de Radiología e Imagen.
}

Hospital Ángeles Mocel, CDMX.

\section{Correspondencia:}

Dra. Carolina González-Vergara

Correo electrónico: carolinavilchis@hotmail.com

Aceptado: 02-08-2020.

www.medigraphic.com/actamedica

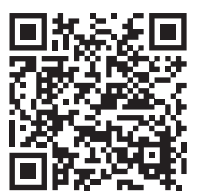




\section{INTRODUCCIÓN}

Un nuevo virus, SARS-CoV-2, agente etiológico de la enfermedad COVID-19, emergió en Wuhan, China en diciembre de 2019. Se reportó en 190 países, con más de 300,000 casos confirmados. ${ }^{1}$

Desde su aparición, y en poco más de cuatro meses, se extendió a un número creciente de países y progresó rápidamente a una pandemia.

El impacto de una epidemia depende del número de personas infectadas, la transmisibilidad de la infección y el espectro de gravedad clínica, por lo que identificar los casos leves permite calibrar la respuesta epidémica. ${ }^{2}$

Hasta el 10 de mayo de 2020, se habían notificado 3,917,366 casos confirmados de enfermedad COVID-19 en 215 países, con 274,361 defunciones reportadas, y para el 17 de junio, a poco más de un mes, la cifra mundial se cuantificó en 8,061,550 con 440,290 fallecimientos. ${ }^{3}$

La evaluación del riesgo por la Organización Mundial de la Salud (OMS) para COVID-19 a nivel mundial, se considera "muy alto", ${ }_{4}^{4}$ cursando con un periodo de incubación corto, pero con un curso clínico largo, con pacientes que tardan muchas semanas en morir o recuperarse.

El primer caso en nuestro país se presentó el 27 de febrero de 2020 en la Ciudad de México, de acuerdo con los registros oficiales, ${ }^{2}$ en un paciente que regresaba de Italia. A pocas horas se confirmaron dos casos más, en ese momento inició la fase 1 epidemiológica.

El primer fallecimiento registrado oficialmente en México ocurrió el día 18 de marzo de 2020. La fase 2 epidemiológica comenzó el 24 de marzo, tras lo cual se implementaron medidas de control para disminuir el riesgo de contagios como la suspensión de actividades económicas, restricción de congregaciones masivas y la recomendación de resguardo domiciliario.

El 30 de marzo de 2020 se intensificaron las medidas de prevención y se declara "emergencia sanitaria", para dar paso a la fase 3 epidemiológica en el país el 21 de abril de 2020, con extensión de medidas sanitarias y de prevención hasta finales del mes de mayo.

Las cifras oficiales en México al 17 de junio de 2020 arrojaron un total de 159,793 casos positivos de COVID-19 y 19,080 muertes, con una tasa de letalidad global de $11.94 \%$, donde destacaba la Ciudad de México y el Estado de México con el mayor número de casos, los cuales, según estimaciones, podrían haber sido mayores en número a nivel nacional de acuerdo con la Organización para la Cooperación y el Desarrollo Económico (OCDE), debido al bajo número de pruebas de detección realizadas por cada 1,000 habitantes. ${ }^{5}$

En el Hospital Ángeles Mocel de la Ciudad de México, el método de detección con el que contamos para el diagnóstico de infección por SARS-CoV-2 es la RT-PCR (reacción en cadena de la polimerasa de la transcriptasa inversa en tiempo real), en su versión cualitativa, operando de acuerdo con el protocolo de Berlín. ${ }^{6}$ Según este estudio, se pueden obtener dos resultados: positivo y negativo para SARS-CoV-2, con base en la detección de material genético viral, en este caso proteína $\mathrm{E}$ o RdRp, y en caso de resultar positivo se reporta también una clasificación leve, moderada o severa de acuerdo con la carga viral estimada mediante la curva de amplificación.

La tomografía computada de tórax no está indicada como estudio de escrutinio; no obstante, puede demostrar alteraciones pulmonares inclusive antes de que la RT-PCR se manifieste como positiva. Tiene grandes ventajas como la rápida adquisición y pronta evaluación en centros que no dependan de la lectura a distancia. En el Hospital Ángeles Mocel, se cuenta con evaluación en sitio las 24 horas, siete días de la semana. La sensibilidad se ha establecido entre 70 y $97 \%$, con una especificidad de hasta $100 \%$, con un valor predictivo positivo que dependerá de la prevalencia de la enfermedad.?

El objetivo de este estudio es correlacionar los hallazgos tomográficos específicos de lesión pulmonar con la estimación de la carga viral determinada por RT-PCR y definir si están relacionados al momento del diagnóstico de enfermedad COVID-19.

\section{MATERIAL Y MÉTODOS}

Realizamos un estudio descriptivo, transversal de una cohorte de pacientes a quienes se les realizó tomografía computada (TC) de tórax y prueba RT-PCR para SARSCoV-2 en un hospital privado de la Ciudad de México (Hospital Ángeles Mocel), en el periodo comprendido del 19 de marzo al 29 de mayo de 2020.

Incluimos a todos los mayores de 18 años que ingresaron a carpa de atención respiratoria por presentar síntomas sugestivos de enfermedad COVID-19, a quienes se realizó prueba RT-PCR por hisopado nasal y faríngeo, así como tomografía computada de tórax.

Los estudios tomográficos se realizaron en fase simple, con un equipo helicoidal Siemens ${ }^{\circledR}$ "SOMATOM go. All" de 64 detectores. Todos los estudios fueron efectuados con alta resolución pulmonar, con colimación de $2 \mathrm{~mm}$ utilizando evaluación mediastinal complementaria y fueron revisados por dos evaluadores experimentados para homologar el criterio de los hallazgos radiológicos, tomando en cuenta: lesiones intersticiales en "vidrio despulido", engrosamientos septales interlobulillares con "patrón adoquinado", bronquioloectasias, consolidación parenquimatosa, neumonía organizada, atelectasias, zonas de fibrosis, linfadenopatía mediastinal o hiliar y derrame pleural. 
Se excluyeron pacientes que en la tomografía computada presentaran imágenes de daño pulmonar distintas a las que caracterizan a la enfermedad por SARS-CoV-2. Se eliminaron aquellos con prueba RT-PCR negativa, así como pacientes en su segunda prueba, segundo estudio tomográfico o controles ulteriores.

Dividimos nuestra muestra en tres grupos, basados en la carga viral encontrada en la prueba RT-PCR para SARSCoV-2. Grupo 1 con carga viral leve; grupo 2 con carga viral moderada y grupo 3 con carga viral severa. Comparamos los diferentes hallazgos en las imágenes de la tomografía de tórax que caracterizan al daño pulmonar asociado a infección por SARS-CoV-2 entre grupos, identificando en cuáles de ellos existen diferencias utilizando el test de ANOVA de un factor. Posterior a su comparación, agrupamos en dos: grupo 1 con carga viral leve-moderada y grupo 2 con carga viral severa, con la intención de identificar la correlación entre los hallazgos tomográficos y la carga viral. Para grupos categóricos utilizamos el test de Kappa-Cohen y Pearson para variables ordinales.

De igual manera, se utilizó el número real de replicaciones virales sobre 40 que tuvo cada paciente y comparamos con cada uno de los hallazgos tomográficos; para observar si existe correlación de alguna, aplicamos el test de Spearman. Se efectuó un análisis descriptivo de los datos. Las variables cuantitativas con distribuciones paramétricas fueron expresadas como media \pm desviación estándar (DE), aquellos con distribución no paramétrica con medianas, mínimos y máximos, y los datos categóricos expresados en porcentajes. Consideramos un valor menor a 0.05 para una p significativa y un intervalo de confianza (IC) de 95\%. ${ }^{8}$ Los datos se analizaron utilizando el Software SPSS (versión 20.0 para Mac).

\section{RESULTADOS}

De una cohorte de 358 pacientes, eliminamos 284, con una muestra total estudiada de 74 pacientes. Se excluyeron pacientes que en la tomografía computada presentaran imágenes de daño pulmonar diferentes al que caracteriza a la enfermedad por SARS-CoV-2, así como pacientes con prueba RT-PCR negativa, repetida, realizada en otra institución o a destiempo de la TC, así como estudios de TC realizados por segunda vez o mayor.

La tomografía computada fue positiva en $93 \%$ de los pacientes.

El $71.6 \%$ de pacientes estudiados fueron del género masculino, con una edad media global de $50.03 \pm 17.41$.

En la prueba de RT-PCR SARS-CoV-2 identificamos una replicación viral media de 25.5 réplicas $( \pm 5.73$ ) sobre 40 y cualitativa moderada en $55.4 \%$ de los pacientes.
Las imágenes con mayor frecuencia encontradas en TC de tórax fueron las opacidades en vidrio despulido en $82.4 \%$ de los pacientes. De éstos, en $80.3 \%$ se encontró de forma bilateral difusa; en $60.7 \%$ del lado derecho y $62.9 \%$ del lado izquierdo. Encontramos consolidación parenquimatosa en $55.4 \%$ de los pacientes, en la gran mayoría $(37.8 \%)$ de forma bilateral, linfadenopatía mediastinal en $71.6 \%$, engrosamiento septal en $56.8 \%$, bronquioloectasias en $48.6 \%$, atelectasias en $40.5 \%$, patrón adoquinado en $35.1 \%$, neumonía organizada en $28.4 \%$ siendo en su mayoría bilateral, zonas de fibrosis en $24.3 \%$, y derrame pleural en $14.9 \%$ de los pacientes (Tabla 1).

Al dividir la muestra en grupos de acuerdo con la carga viral, identificamos que no existen diferencias significativas en ninguno (Tabla 2).

De la misma forma, al realizar la prueba de KappaCohen y de Spearman para mostrar correlación entre cada uno de los hallazgos tomográficos y la carga viral (tanto cualitativa como cuantitativa), no existen diferencias significativas para ninguna de las variables de imagen estudiadas,

Tabla 1: Análisis de edad, género, RT-PCR SARS-CoV-2 y hallazgos iniciales en estudio de tomografía computada de tórax. N = 74 pacientes.

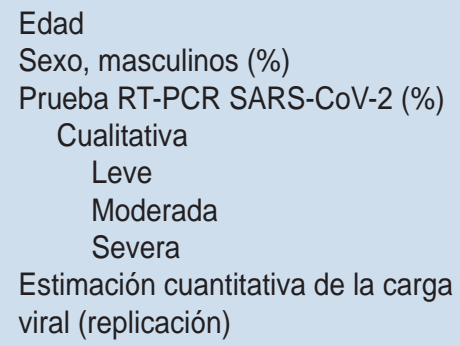

Hallazgos iniciales en tomografía computada de tórax n (\%)

$\begin{array}{lc}\text { Vidrio despulido } & 61(82.43) \\ \text { Linfadenopatía } & 53(71.6) \\ \text { Consolidación } & 41(56.76) \\ \quad \text { Derecha } & 11(14.9) \\ \quad \text { Izquierda } & 2(2.7) \\ \text { Bilateral } & 28(37.8) \\ \text { Engrosamiento septal } & 42(56.8) \\ \text { Bronquioloectasias } & 36(48.6) \\ \text { Atelectasia } & 30(40.5) \\ \text { Patrón adoquinado } & 26(35.1) \\ \text { Neumonía organizada } & 21(28.4) \\ \quad \text { Unilateral } & 3(4.1) \\ \text { Bilateral } & 18(24.3) \\ \text { Fibrosis } & 18(24.3) \\ \text { Derrame pleural } & 11(14.9)\end{array}$


Tabla 2: Relación de grupos con carga viral en cada una de las variables de edad, género y hallazgo tomográfico.

\begin{tabular}{|c|c|c|c|c|}
\hline & $\begin{array}{c}\text { Grupo } 1 \\
n=15(\%)\end{array}$ & $\begin{array}{c}\text { Grupo } 2 \\
n=41(\%)\end{array}$ & $\begin{array}{c}\text { Grupo } 3 \\
n=18(\%)\end{array}$ & $\mathrm{p}$ \\
\hline Edad & $33.13 \pm 16.16$ & $52.54 \pm 17.95$ & $49.22 \pm 16.72$ & 0.275 \\
\hline Sexo masculino, $n=53$ & $10(18.9)$ & $33(62.3)$ & $10(18.9)$ & 0.389 \\
\hline Vidrio despulido, $n=60$ & $10(16.7)$ & $38(63.3)$ & $12(20.0)$ & 0.806 \\
\hline Linfadenopatía, $n=53$ & $11(20.8)$ & $30(56.6)$ & $12(22.6)$ & 0.655 \\
\hline Consolidación, $n=41$ & $7(46.7)$ & $26(63.4)$ & $8(44.4)$ & 0.300 \\
\hline Engrosamiento septal, $n=42$ & $10(23.8)$ & $22(52.4)$ & $10(23.8)$ & 0.560 \\
\hline Bronquioloectasias, $n=36$ & $6(16.7)$ & $26(72.2)$ & 4 (11.1) & 0.211 \\
\hline Atelectasia, $n=30$ & $6(20.0)$ & $16(53.3)$ & $8(26.7)$ & 0.778 \\
\hline Patrón adoquinado, $n=26$ & 7 (26.9) & $15(57.7)$ & $4(15.4)$ & 0.140 \\
\hline Neumonía organizada, $n=21$ & $3(14.3)$ & $14(66.7)$ & $4(19.0)$ & 0.973 \\
\hline Fibrosis, $n=18$ & $5(27.8)$ & $10(55.6)$ & $3(16.7)$ & 0.271 \\
\hline Derrame pleural, $n=11$ & $4(36.4)$ & $4(36.4)$ & $3(27.3)$ & 0.499 \\
\hline
\end{tabular}

por lo que concluimos que no existe correlación alguna con la carga viral; sin embargo, el sexo masculino sí tiene correlación con mayor replicación viral, por lo que deberá estudiarse su relación con la morbimortalidad (Tablas 3 y 4).

Encontramos un pequeño número de pacientes $(\mathrm{n}=5)$ con una edad media de 28.8, todos del género masculino, con estudios tomográficos dentro de límites normales. Dos de ellos con RT-PCR cualitativa leve (40\%) y 3 severa (60\%). El curso clínico en este último grupo deberá ser estudiado.

\section{DISCUSIÓN}

Coronavirus pertenece a la familia Coronaviridae, y se han identificado hasta este momento seis cepas: HCoV-229E, HCoV-HKU1, HCoV-OC43, HVoV-NL63, Coronavirus del síndrome respiratorio agudo severo (SARS-CoV) y coronavirus del síndrome respiratorio de Medio Oriente (MERSCoV), siendo los últimos dos los causantes de pandemias. ${ }^{9}$

El $13.8 \%$ de los pacientes afectados por el nuevo virus SARS-CoV-2 evolucionan a enfermedad grave; es por esto que la detección temprana del RNA viral es necesaria para lograr contener las fuentes de infección y la progresión de la enfermedad.

El estándar de oro para la detección es la reacción en cadena de la polimerasa, PCR por sus siglas en inglés, un método enzimático que posee una alta sensibilidad y especificidad. La PCR de la transcriptasa inversa en tiempo real (RT-PCR) posee una ventaja al ser un estudio cuantitativo simple mucho más específico y sensible, permitiendo identificar los distintos tipos de coronavirus. ${ }^{9}$ Yu y su equipo desarrollaron un ensayo de RT-PCR en tiempo real, en el que fue posible detectar como límite inferior 10 copias $/ \mathrm{mL}^{10}$
Las mediciones de la carga viral en muestras de tejido son indicativas de replicación viral activa y utilizadas de forma rutinaria, como ya se ha mencionado, para monitorizar y pronosticar tanto la progresión clínica como la respuesta al tratamiento. Distintos estudios han demostrado que la carga viral es igualmente alta entre pacientes sintomáticos y asintomáticos, por lo que la dinámica de la carga en vías respiratorias inferiores y la gravedad de la enfermedad es aún desconocida. No obstante, Shufa Zheng afirma en su ensayo clínico que aquellos con enfermedad grave muestran una carga significativamente mayor que aquellos con enfermedad leve, siendo hasta 60 veces más alta. ${ }^{1,11}$

Tal y como se ha visto en la práctica clínica, y acorde con nuestros resultados, el género masculino evoluciona en un peor desenlace, por lo que se ha intentado establecer una relación entre el sexo y la duración de la carga, la cual es más prolongada en hombres que en mujeres, esto se atribuye a las diferencias en el estado inmune y a la regulación hormonal, aunque no está esclarecido por completo. Así mismo, se ha encontrado esta correlación con la edad, lo que se traduce en una alta tasa de enfermedad grave en adultos mayores de 60 años, secundario a la inmunosenescencia y a la presencia de niveles más altos de la enzima convertidora de angiotensina 2 en los alveolos. ${ }^{1}$

Estudios previos han logrado determinar la duración media del virus en las muestras, siendo el promedio de 18 días. Se había informado que la carga viral del síndrome respiratorio agudo severo presentaba picos de replicación dentro de la primera semana después del inicio de los síntomas; sin embargo, pacientes con insuficiencia respiratoria aguda grave presentaron el pico de replicación después de 10 a 12 días, aproximadamente, 
Tabla 3: Correlación de carga viral cualitativa por grupos, edad, sexo y hallazgos tomográficos.

Prueba de Kappa-Cohen, $n=74$

\begin{tabular}{|c|c|c|c|c|}
\hline & $\begin{array}{c}\text { Grupo } 1 \\
\text { Leve-moderado } n=56(\%)\end{array}$ & $\begin{array}{c}\text { Grupo } 2 \\
\text { Severo } n=18(\%)\end{array}$ & Correlación & $p$ \\
\hline Edad & $49.05( \pm 18.80)$ & $49.22( \pm 16.72)$ & 0.083 & 0.531 \\
\hline Sexo, $n=53$ & $10(13.5)$ & $43(58.1)$ & 0.258 & 0.049 \\
\hline Vidrio despulido, $n=60$ & $10(13.5)$ & $50(67.6)$ & 0.185 & 0.110 \\
\hline Linfadenopatía, $n=53$ & $11(14.9)$ & $42(56.8)$ & 0.019 & 0.869 \\
\hline Consolidación, $n=41$ & $33(44.5)$ & $8(10.8)$ & 0.091 & 0.388 \\
\hline Engrosamiento septal, $n=42$ & $10(13.5)$ & 32 (43.2) & 0.087 & 0.386 \\
\hline Bronquioloectasias, $n=36$ & $6(8.1)$ & $30(40.5)$ & 0.069 & 0.453 \\
\hline Atelectasia, $n=30$ & $6(8.1)$ & $24(32.4)$ & 0.004 & 0.962 \\
\hline Patrón adoquinado, $n=26$ & $7(9.5)$ & $19(25.7)$ & 0.079 & 0.295 \\
\hline Neumonía organizada, $n=21$ & $3(4.1)$ & $18(24.3)$ & 0.054 & 0.420 \\
\hline Fibrosis, $n=18$ & $5(6.8)$ & $13(17.6)$ & 0.056 & 0.362 \\
\hline Derrame pleural, $n=11$ & $4(5.4)$ & $7(9.5)$ & 0.067 & 0.150 \\
\hline Replicación & & & 0.819 & 0.000 \\
\hline
\end{tabular}

manteniéndose baja durante los primeros 12.1,11 Esto tiene una relación directa en la progresión tomográfica de los hallazgos. En los casos leves se descubrió que el aclaramiento viral ocurría al décimo día, y 90\% de los pacientes presentaban una prueba negativa. ${ }^{11}$

La RT-PCR debe realizar un determinado número de ciclos de amplificación del material genético de la muestra dada (para este caso entre 35-45) para poder detectar y amplificar correctamente el material genético que se desea estudiar, esto ampliamente relacionado con la carga viral en la muestra dada, ya que a mayor carga viral se requerirá un menor número de ciclos para comenzar la detección y amplificación del material genético deseado, así al reportar el resultado obtenido de la muestra se registran los siguientes datos:

1. Presencia o ausencia de carga viral dependiendo de la detección y amplificación del material genético deseado.

2. Número de ciclo en el que ocurrió por primera vez detección y amplificación del material genético, sobre el número total de ciclos realizados durante el procedimiento.

3. Estimación de carga viral de acuerdo con la cantidad de ciclos necesarios para detectar y amplificar el material genético, la cual se clasificará en leve, moderada o severa, de acuerdo con la cantidad de ciclos necesarios para detección y amplificación, siendo indirectamente proporcional al número de ciclos requeridos para su detección y amplificación.
Al contar con un reporte que nos permite estimar y clasificar la carga viral detectada en una muestra, podemos utilizar esta información para correlacionar datos clínicos y paraclínicos encontrados durante la evolución de esta enfermedad, de manera que si bien no nos permite conocer la carga viral exacta en cada paciente, nos da la oportunidad de poder identificar las posibles diferencias en cuanto a manifestaciones clínicas y paraclínicas durante el desarrollo de esta infección en pacientes con mayor o menor carga viral.

\begin{tabular}{|c|c|c|c|}
\hline \multicolumn{4}{|c|}{ Prueba de Spearman } \\
\hline & Replicación & Correlación & $p$ \\
\hline Sexo, masculino & $25.81(5.39)$ & 0.258 & 0.049 \\
\hline Vidrio despulido & $25.52 \pm 5.173$ & 0.019 & 0.875 \\
\hline Linfadenopatía & $25.94 \pm 5.430$ & 0.129 & 0.272 \\
\hline Consolidación & $26.29 \pm 5.290$ & 0.148 & 0.208 \\
\hline Engrosamiento septal & $26.24 \pm 5.360$ & 0.136 & 0.247 \\
\hline Bronquioloectasias & $26.25 \pm 4.780$ & 0.134 & 0.255 \\
\hline Atelectasia & $25.77 \pm 5.770$ & 0.320 & 0.789 \\
\hline Patrón adoquinado & $27.04 \pm 5.295$ & 0.189 & 0.107 \\
\hline Neumonía organizada & $26.81 \pm 5.260$ & 0.141 & 0.230 \\
\hline Fibrosis & $26.50 \pm 6.030$ & 0.095 & 0.419 \\
\hline Derrame pleural & $26.73 \pm 6.840$ & 0.096 & 0.415 \\
\hline Replicación & & 0.819 & 0.000 \\
\hline
\end{tabular}



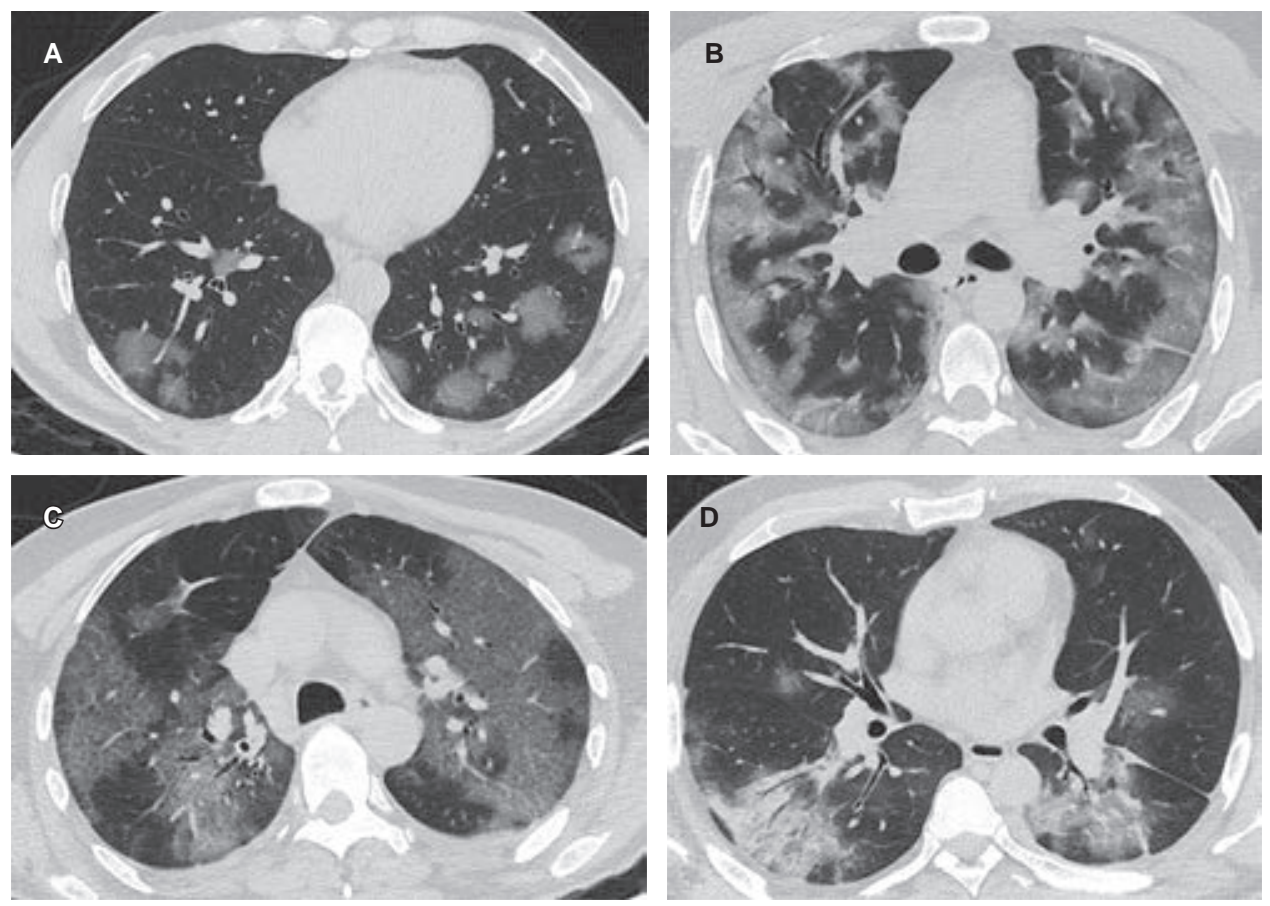

Figura 1:

Hallazgos tomográficos por afectación intersticial en enfermedad COVID-19.

A) Lesiones redondeadas bilaterales centrales y periféricas en "vidrio despulido". B) Distribución difusa de lesión intersticial en "vidrio despulido".

C) Patrón adoquinado secundario a engrosamiento de septos interlobulillares. D) Bronquioloectasias periféricas valoradas en el segmento posterior del lóbulo superior derecho.

Los hallazgos tomográficos corresponden al daño pulmonar ocasionado por SARS-CoV-2, el cual está relacionado con la utilización de la enzima convertidora de angiotensina 2 como receptor celular en los humanos, lo que causa daño intersticial inicial con el subsecuente daño parenquimatoso. ${ }^{12}$ De allí que las manifestaciones tomográficas que se observan con mayor frecuencia son las "opacidades en vidrio despulido" (82.4\% de nuestra serie), que son habitualmente redondeadas de bordes mal definidos, con mayor atenuación que el pulmón que les rodea, pudiendo visualizar las estructuras vasculares en su interior, las cuales ocurren por la afectación intersticial desde etapas tempranas. ${ }^{13}$ Pueden ser periféricas, centrales, multifocales o difusas y la imagen tomográfica es producida por la ocupación parcial del espacio aéreo, y representa engrosamiento intersticial alveolar o septal que clínicamente corresponde con ocupación alveolar temprana parcial con aumento del volumen sanguíneo capilar y colapso parcial de los alveolos (Figura 1). ${ }^{14,15}$

La progresión del daño intersticial por el incremento en el acúmulo de líquido o de células es hacia el engrosamiento de los septos o tabiques interlobulillares que separan a los lobulillos pulmonares secundarios, los cuales son imperceptibles en condiciones normales. La formación de este patrón radiológico de imagen reticular está asociado a infiltración intersticial de linfocitos como causantes del engrosamiento $\operatorname{septal}^{16}(56.8 \%$ en nuestra serie). Tomográficamente se observan como líneas cortas que se extienden hacia la pleura en la periferia pulmonar o como imágenes poliédricas que delimitan uno o más lobulillos adoptando un "patrón adoquinado", el cual aparenta un pavimento irregular (crazy paving pattern) superponiéndose como imágenes reticulares sobre las zonas en vidrio despulido, observado en $35.1 \%$ de los pacientes de nuestra serie (Figura 1). ${ }^{13,14,17}$

Las consolidaciones parenquimatosas (55.4\% en nuestra serie) en COVID-19 están condicionadas por ocupación del espacio aéreo relacionado con exudado celular fibromixoide en los alveolos. ${ }^{18}$ Se manifiestan tomográficamente como zonas de alta atenuación que, a diferencia de la opacidad en vidrio despulido, borran las imágenes vasculares y las paredes de las vías respiratorias con poca pérdida en el volumen pulmonar. Pueden asociarse o no a broncograma aéreo. Cuando son múltiples, de distribución central, basal o broncocéntrica, asociadas a lesión intersticial o engrosamientos septales e imágenes pseudonodulares debe considerarse el término de "neumonía organizada" (28.4\%), la cual en enfermedad COVID-19 se asocia a datos de neumonía intersticial aguda con edema y formación de membranas hialinas de predominio en los segmentos declives, y que en una fase posterior hay franca organización del espacio intersticial con opacidades reticulares y bronquiectasias por tracción (Figura 2). ${ }^{13}$

Las bronquioloectasias ( $48.6 \%$ de nuestra serie) son el resultado de la obstrucción de la vía aérea con dificultad para el drenaje, asociada a la ocupación del espacio aéreo por moco gelatinoso, demostrado en casos de autopsias que conllevan a la dilatación anormal y permanente de los bronquios y bronquiolos con engrosamiento y destrucción 
de sus paredes. Tomográficamente se visualizan como espacios tubulares aéreos que pueden verse hasta cerca de $1 \mathrm{~cm}$ de la pleura (Figura 1).12-14

Desde el inicio de la enfermedad podemos observar adenopatías inflamatorias mediastinales o hiliares, las cuales deben medir más de $10 \mathrm{~mm}$ en su eje corto para considerar la etiología inflamatoria, habiéndose observado en $71.6 \%$ de los casos.

El resultado de inflamación progresiva rápida o crónica conlleva a engrosamiento septal de tipo fibroso (24.3\%), alternado con zonas de atelectasia (40.5\%), que algunos autores han sugerido como una fase de estabilización de la enfermedad. ${ }^{12}$ Estos hallazgos traducen, sin duda, que el diagnóstico realizado no corresponde en tiempo con el inicio de la enfermedad (Figura 2).

La presencia de derrame pleural de $14.6 \%$ en nuestra serie es mucho mayor a la reportada por autores asiáticos, por lo que requiere investigación en la correlación con otras patologías asociadas y deberemos esperar otros reportes en pacientes mexicanos para realizar análisis comparativo.

Con mayor número de pacientes en la muestra reduciríamos un error Beta, incrementando el poder estadístico; y debido a que muchos de los pacientes continúan tratamiento en casa no fue posible llevar seguimiento de la morbimortalidad.

No haber encontrado correlación de los hallazgos tomográficos específicos con la carga viral pudo haberse debido al tiempo en el que se efectuó la TC, en la que aún no se manifestaban grandes cambios. Este hallazgo no disminuye la sensibilidad probada de la TC para el diagnóstico radiológico, por lo que un estudio posterior deberá puntualizar el número de día en el que se realice la tomografía en relación con la aparición de la sintomatología para establecer en específico su valor pronóstico, ya que a mayores cambios tomográficos mayor deberá ser la morbimortalidad. Invitamos a otras unidades a realizar trabajos prospectivos para evaluar la evolución clínica tomando en cuenta las variables ya comentadas.

\section{CONCLUSIÓN}

Al día de hoy, a diferencia de la realización de la prueba RT-PCR, la tomografía computada de tórax no puede establecerse como estudio de detección ni de escrutinio; sin embargo, su alta sensibilidad evidencia alteraciones intersticiales que pasan desapercibidas en una placa de tórax, y con esto se podrá establecer su recomendación como uso rutinario en un futuro próximo. El conocimiento a detalle de los hallazgos tomográficos impera, debido a que la infección por SARS-CoV-2 comparte características con otras neumonías virales ocasionadas por virus de la misma familia (SARS y MERS) y ya forma parte de los diagnósticos diferenciales clínico-radiológicos.
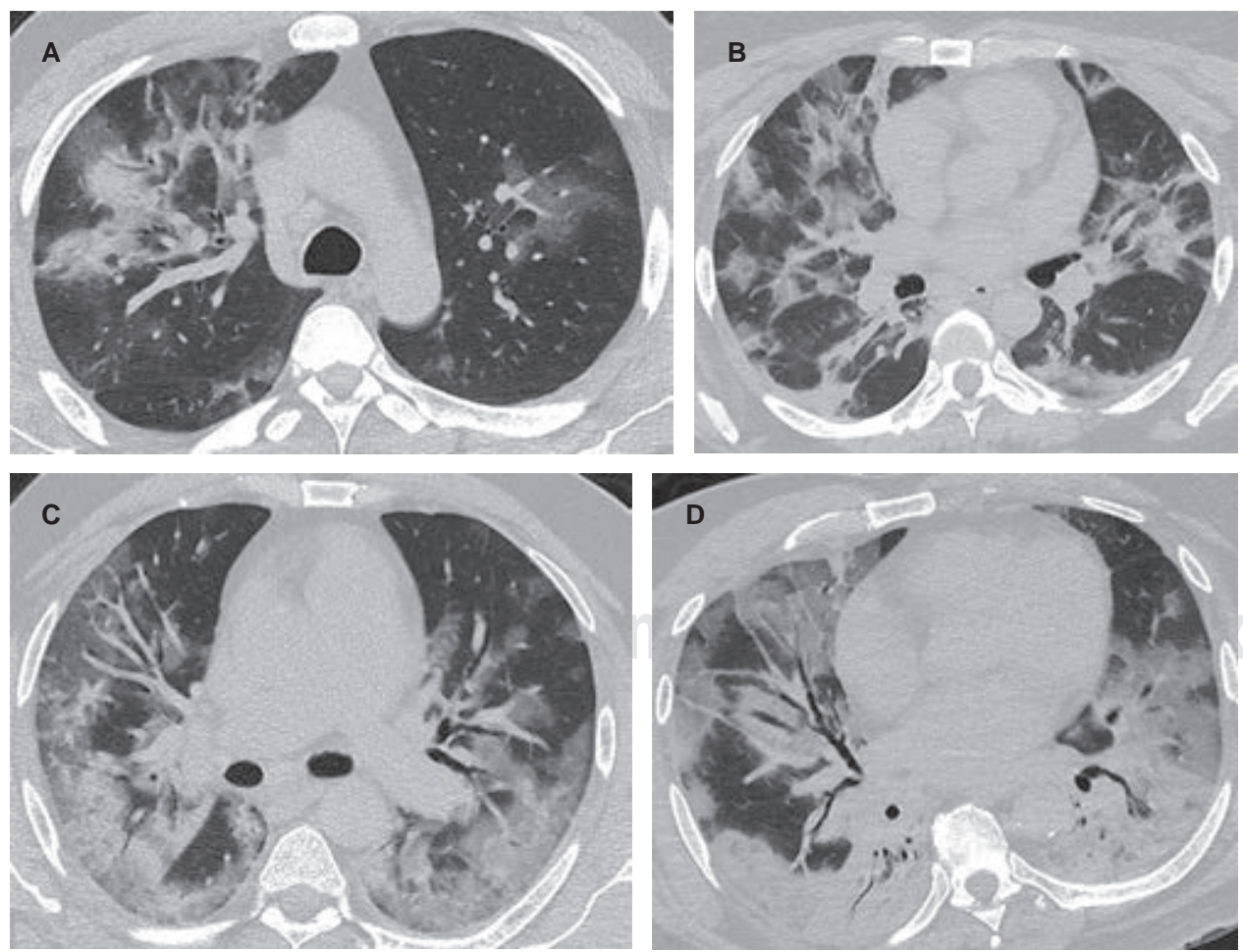

Figura 2:

A) Consolidaciones parenquimatosas. B) Engrosamientos septales asociados a ocupación del espacio aéreo. C y D) Neumonía organizada con broncograma aéreo y bronquioloectasias. 


\section{REFERENCIAS}

1. Zheng S, Fan J, Yu F, Feng B, Lou B, Zou Q et al. Viral load dynamics and disease severity in patients infected with SARS-CoV-2 in Zhejiang province, China, January-March 2020: retrospective cohort study. BMJ. [Internet] 2020 [Cited 27 April 2020]; 369 (1443): 1-8. Available in: http://dx.doi.org/10.1136 bmj.m1443.

2. Bi Q, Wu Y, Mei S, Ye C, Zou X, Zhang Z et al. Epidemiology and transmission of COVID-19 in 391 cases and 1286 of their close contacts in Shenzhen, China: a retrospective cohort study. Lancet Infect Dis. 2020; 20 (8): 911-919. doi: 10.1016/s14733099(20)30287-5.

3. Comunicado Técnico Diario COVID-19 MÉXICO. 2020. Disponible en: https://www.gob.mx/cms/uploads/attachment/file/558320/ Comunicado_Tecnico_Diario_COVID-19_2020.06.17.pdf.

4. Organización Panamericana de la Salud/Organización Mundial de la Salud. Actualización epidemiológica: enfermedad por coronavirus (COVID-19). 10 de mayo de 2020, Washington, D.C.: OPS/OMS; 2020. https://www.paho.org/es.

5. Noticias-america-latina-51959283@www.bbc.com [Internet]. Disponible en: https://www.bbc.com/mundo/noticias-americalatina-51959283.

6. Corman VM, Landt O, Kaiser M, Molenkamp R, Meijer A, Chu D et al. Diagnostic detection of 2019-CoV by real time RT-PCR. Euro Surveill. 2020 [Cited 30 April 2020]; 25 (14): 20200409c. Available in: https://www.ncbi.nlm.nih.gov/pmc/articles/PMC6988269/.

7. Ai T, Yang Z, Hou H, Zhan C, Chen C, Lv W et al. Correlation of Chest CT and RT-PCR testing in coronavirus disease 2019 (COVID-19) in China: a report of 1,014 cases. Radiology. 2020; 296 (2): E32-E40. Available in: https://doi.org/10.1148/radiol.2020200642.

8. Saucedo ME, Fenig J. Estadística en cirugía, cómo entender y aplicar conceptos básicos. Cir Cir. 2019; 87: 692-697.

9. Shen M, Zhou Y, Ye J, Abdullah AL-maskri A, Kang Y, Zeng $S$ et al. Recent advances and perspectives of nucleic acid detection for coronavirus. Journal of Pharmaceutical Analysis. 2020; 10 (2): 97-101. Available in: https://doi.org/10.1016/j.jpha.2020.02.010.

10. Yu XF, Pan JC, Ye R, Xiang HQ, Kou Y, Huang ZC. Preparation of armored RNA as a control for multiplex real-time reverse transcription-PCR detection of influenza virus and severe acute respiratory syndrome coronavirus. J Clin Microbiol. 2008; 46 (3): 837-841. Available in: https://pubmed.ncbi.nlm.nih.gov/18160451/.

11. Liu Y, Yan L, Wan L, Xiang T, Le A, Liu J et al. Viral dynamics in mild and severe cases of COVID-19. The Lancet Infectious Diseases.
2020; 20 (6): 656-657. Available in: https://doi.org/10.1016/S14733099(20)30232-2.

12. Ye Z, Zhang Y, Wang Y, Huang Z, Song B. Chest CT manifestations of new coronavirus disease 2019 (COVID-19): a pictorial review. Eur Radiol. 2020; 30: 4381-4389. Available in: https://doi.org/10.1007/ s00330-020-06801-0.

13. Hansell D, Bankier A, MacMahon H, McLoud T, Müller N, Remy J. Fleischner society: glossary of terms for thoracic imaging. Radiology. 2008; 246 (3): 697-722.

14. Müller N, Fraser R, Colman N, Paré P. Diagnóstico radiológico de las enfermedades del tórax. Madrid: Elsevier Science; 2003, pp. 70-84.

15. Stark P, Finley G. High resolution computed tomography of the lung [Internet]. Uptodate.com. 2020. Available in: https://www. uptodate.com/contents/high-resolution-computed-tomographyof-the-lungs? search = pathogenesis $\% 20$ lung\%20ground $\% 20$ glass \&source $=$ search_result $\&$ selectedTitle $=2 \sim 150 \&$ usage type $=$ default\&display_rank $=2 \# \mathrm{H} 35$.

16. Xu Z, Shi L, Wang Y, Zhang J, Huang L, Zhang C et al. Pathological findings of COVID-19 associated with acute respiratory distress syndrome. The Lancet Respiratory Medicine. 2020; 8 (4): 420-422. Available in: https://doi.org/10.1016/S2213-2600(20)30076-X.

17. Raghu G, Mikacenic C. Pathogenesis of idiopathic pulmonary fibrosis [Internet]. Uptodate.com. 2020. Available from: https://www. uptodate.com/contents/pathogenesis-of-idiopathic-pulmonaryfibrosis?search = patophisiology $\% 20$ pulmonary $\% 20$ fibrosis $\% 20$ radiology\&source $=$ search_result\&selectedTitle $=1 \sim 150 \&$ usag e_type $=$ default\&display_rank $=1 \# \mathrm{H} 7$.

18. Kanne J. Chest CT findings in 2019 novel coronavirus (2019-nCoV) Infections from Wuhan, China: key points for the radiologist. Radiology. 2020; 295 (1): 16-17. Available in: https://doi. org/10.1148/radiol.2020200241.

Conflicto de intereses y financiamiento: Carolina González, Rosa Esther Arias, Jorge Villalón, Mariana Delgado, Eric Misael Saucedo, Catherine V Rodríguez, Daniel Guerrero, Carolina Andrea Pérez, Brenda A Domínguez y Rubén Uriostegui declaran que no tienen ningún conflicto de intereses. Financiamiento: ninguno. 